\title{
MIT gets plugged in for global data archive
}

Declan Butler

Plans by the Massachusetts Institute of Technology (MIT) look set to transform the way in which academics publish and archive their results and raw data.

On 4 November, the institute will launch its DSpace electronic archive, a joint venture with technology firm Hewlett-Packard of Palo Alto, California.

The ultimate goal of the system is to capture MIT's entire intellectual output in a stable archive, and to extend it to create a seamless global network of similar archives at other research institutions. These multiple databases could be searched as if they were a single entity, and specialized collections could be built by drawing data from participating archives.

More than 40 academic institutions worldwide are considering adopting DSpace, and seven universities, including the University of Cambridge in Britain, are installing and evaluating the system. The move towards such archives is in part driven by libraries, which are looking for cheaper alternatives to costly academic journals.

The technology involved is not rocket science, admits MacKenzie Smith, associate director for technology at MIT Libraries and head of the DSpace project. The main innovation is in transforming the often anarchic sprawl of researchers' websites into a professionally managed system, she says. Documents uploaded onto Dspace must be carefully tagged with 'metadata' codes, such as subject keywords, which will help search engines to navigate the database.

DSpace should also spare MIT researchers much of the hassle of setting up and maintaining their own websites. The system supports a huge variety of file formats, allowing users to make anything from preprints to medical images available online. It also lets users attach other features to their documents, such as software that can manage access to restricted material.

But Smith warns that getting busy faculty members to provide high-quality metadata on their material is a big obstacle, and could deter many would-be participants. "You find that users are not beating down your door," says Eric Van de Velde, director of library information technology at the California Institute of Technology, who has developed a similar, smaller-scale institutional archive.

To get enough data onto the system to make it useful, DSpace has grouped content around individual departments or labs that have well-organized publishing activities. The launch version of DSpace includes five of these 'early adopter' communities such as MIT's Department of Ocean Engineering and MIT Press. The groups have already placed about 750 documents on the database.

Smith says that a major demand from researchers is the storage of their raw data, such as medical images and other large data files. "A lot of these deserve to be managed and preserved as much as the publications that result from them," she says. She is also talking to publishers about the possibility of linking papers in their journals to supplementary information and data stored in the DSpace network of archives.

DSpace may also provide a more solid foundation for preprints than existing servers, but it can also support journals and new forms of information sharing, which could help libraries to cut down on journal subscription costs. In the long term, many academic centres feel that they need to retain control of more of what they produce, and DSpace may be a first step in that direction. www.dspace.org

\section{Developing nations take initiative on greenhouse gases}

\section{Geoff Brumfiel, Washington}

Some of the world's largest developing nations are already reducing their greenhouse-gas emissions - even though they have not yet been set targets. So says a report from the Washington-based Pew Center on Global Climate Change and the Battelle Memorial Institute, a private research organization based in Columbus, Ohio.

The report's authors say that this should be food for thought for the United States and Australia, which reject current attempts to limit their emissions in part because developing nations are exempt from such targets.

The study, which was released on 24 October, says that schemes implemented by Brazil, China, India, Mexico, South Africa and Turkey have together reduced the growth of their greenhouse-gas emissions by some $\mathbf{3 0 0}$ million tonnes per year over the past 30 years. The savings are the result of a wide range of programmes, from local renewable energy schemes to market reforms. In Brazil, for example, tax incentives are offered to families that buy smaller, more fuelefficient cars, says William Chandler, an energy-policy expert who works for Battelle at the Pacific Northwest National

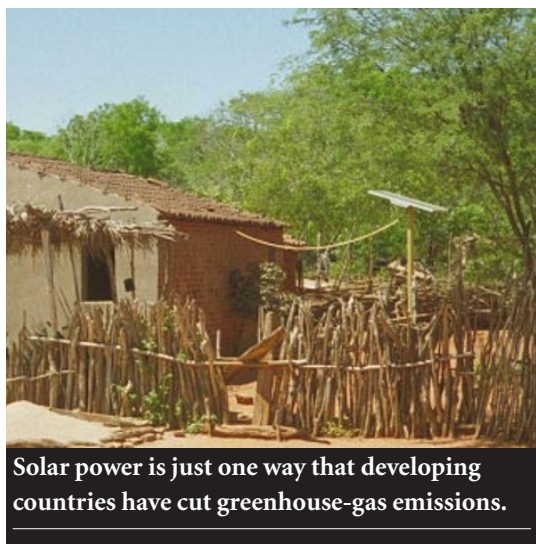

Laboratory in Richland, Washington.

Such projects are voluntary under the

first phase of the Kyoto Protocol, the international agreement on limiting greenhouse-gas emissions. Developing countries won exemption from emissions targets on the grounds that limits might hinder growth and that the developed world is historically responsible for the build-up of greenhouse gases. The United States and Australia cite this as a reason for rejecting the treaty (see Nature 390, 215-216; 1997), but Chandler says the report shows that some progress is being made without targets.
The report may also aid negotiations for the second phase of the protocol, which which will cover emissions targets after 2012. Developing countries are likely to have to accept targets for this period, and they will need to have a quantitative understanding of their emissions to do so, says Tony La Vina, a senior fellow at the World Resources Institute, an environmental think-tank in Washington DC. "This study shows that it's possible," he notes.

But the report will probably not be enough to convince opponents of Kyoto that developing countries are doing their bit, says Mahendra Shah, a senior scientist at the International Institute for Applied Systems Analysis, an interdisciplinary think-tank in Laxenburg, Austria. "I think opponents will brush this report off because it is not comprehensive enough," he says.

In many developing countries, Shah points out, agriculture and forestry are the primary sources of greenhouse gases, but these sectors were not fully investigated in the report. Without a clear understanding of how these areas contribute to the picture, it will be difficult to convince the United States that developing countries really are working to reduce emissions, he says. 